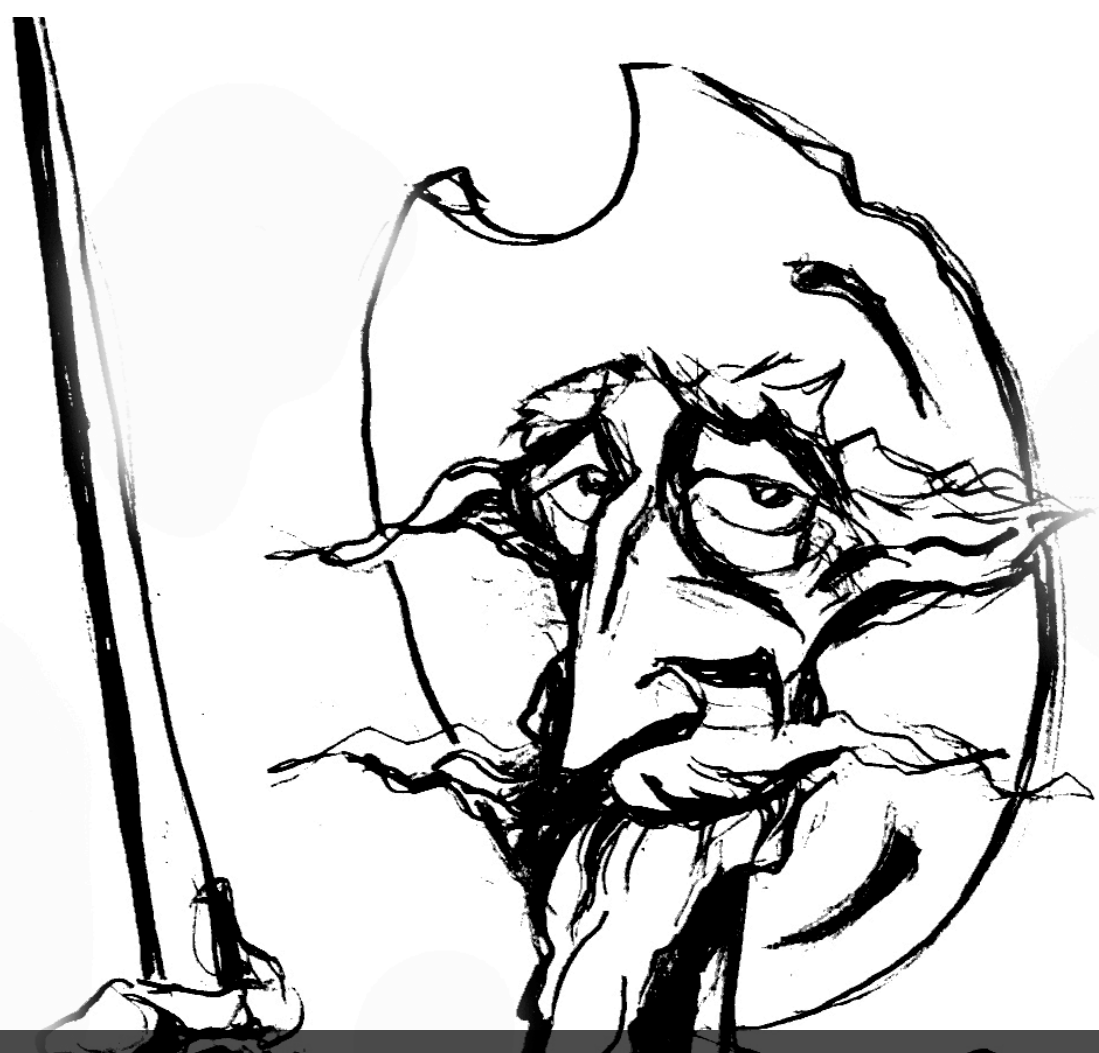

El factor Rosas.

Discusion sobre Juan Manuel de Rosas. La construcción de un liderazgo político, de Raúl O. Fradkin y Jorge Gelman

[Roy Hora, Raúl Fradkin, Jorge Gelman] 


\title{
El factor Rosas. Juan Manuel de Rosas. La construcción de un liderazgo político de Raúl O. Fradkin y Jorge Gelman
}

\author{
The Rosas factor. On Juan Manuel de Rosas. La construcción de un liderazgo \\ político by Raúl O. Fradkin and Jorge Gelman
}

ROY HORA

\section{Resumen}

Este texto analiza la biografía de Juan Manuel de Rosas escrita por Raúl O. Fradkin y Jorge Gelman. El trabajo sitúa esta biografía en relación con estudios anteriores y analiza sus principales contribuciones. Finalmente, discute las ventajas y limitaciones del modo en que los autores enfocan el problema de la relación entre Rosas como líder político y el contexto en el que desarrolló su carrera.

Palabras clave: Juan Manuel de Rosas historia - biografía - Raúl O. Fradkin - Jorge Gelman

\begin{abstract}
This short essay discusses Raúl O. Fradkin's and Jorge Gelman's book on the Argentine dictator Juan Manuel de Rosas. It analyses how Fradkin's and Gelman's work relates to earlier works on Rosas, and highlights its most significant historiographical contributions. Finally, it analyses how the authors deal with the issue of Rosas's political agency.
\end{abstract}

Keywords: Juan Manuel de Rosas - history - biography - Raúl O. Fradkin - Jorge Gelman

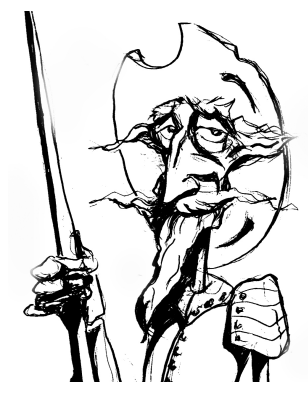

Recibido con pedido de publicación el 5 de octubre de 2016

Aceptado para su publicación el 30 de octubre de 2016

Versión definitiva recibida el 15 de noviembre de 2016

Roy Hora, Universidad Nacional de Quilmes, Consejo Nacional de Investigaciones Científicas y Técnicas, Argentina; e-mail: rhora@unq.edu.ar 
Quisiera comenzar agradeciendo a los organizadores de esta jornada la oportunidad de comentar este Juan Manuel de Rosas, un trabajo rico y detallado, que ha demandado mucha investigación de archivo y que revela un gran dominio de la literatura relevante. El libro de Raúl Fradkin y Jorge Gelman se va ganar un lugar de privilegio en la lista de grandes biografías sobre el dictador inaugurado hace casi un siglo por Carlos Ibarguren con su Juan Manuel de Rosas, su vida, su drama y su tiempo, y continuada por Manuel Gálvez con su Vida de Don Juan Manuel de Rosas, y luego por Julio Irazusta con su Vida política de Juan Manuel de Rosas a través de su correspondencia. En particular, este trabajo se mide con el último estudio de envergadura, y el más académico, sobre el Restaurador de las Leyes. Me refiero al Juan Manuel de Rosas que John Lynch publicó en inglés en 1981 y que, traducido al castellano pocos años más tarde, pronto se erigió en el texto de referencia sobre la figura más idiosincrática de nuestro siglo XIX.

¿Cuáles son las principales novedades que nos ofrece la incursión de Fradkin y Gelman en la vida del Rosas, y en qué medida esta biografía se aparta del modelo que ofrecía el estudio de Lynch? Lo primero que me gustaría señalar es que en ambos trabajos el enfoque es similar: Rosas es situado en su contexto histórico, y es este nivel de análisis el que le otorga inteligibilidad y norte al relato biográfico (retomaré este punto más adelante). Las estructuras económicas, las formas de autoridad, los procesos de cambio político, todas estas dimensiones sirven para situar y explicar la trayectoria y las características de la vida pública del estanciero de Los Cerrillos. Para decirlo en pocas palabras, esta nueva biografía no aparece motivada por el deseo de responder interrogantes referidos a la personalidad del Restaurador, o a su singularidad y su impacto en la vida pública del país. Más bien, su legitimidad como objeto de indagación histórica nace de la maduración, en el período que media entre la aparición de la biografía de Lynch y nuestro propio tiempo, de una nueva imagen sobre la sociedad bonaerense y, a partir de allí, de la necesidad de encuadrar a la figura de Rosas en esta nueva estación historiográfica.

Como sabemos, en las últimas tres décadas nuestra visión sobre el escenario en el que se desplegó la carrera de Rosas ha cambiado de manera sustantiva. No es esta la ocasión para detenernos a evaluar esos cambios, y solo menciono dos importantes elementos que signan el nuevo cuadro, y que definen los grandes parámetros en los que se mueve esta biografía. Por una parte, y a diferencia de lo que pensaba Lynch, hoy está claro que Rosas ya no puede ser concebido como el producto de una sociedad crecida a la sombra de la estancia. En este sentido, la figura política del dictador no puede entenderse como una prolongación o como un derivado de su posición prominente como actor de la sociedad rural y la economía ganadera. El segundo elemento a tener en cuenta es que, descartada la idea del poder privado como clave de las formas de autoridad construidas tras la independencia, el marco político en el que es 
preciso situar al personaje es el de un orden republicano en formación, caracterizado por elevados niveles de participación popular.

A partir de estos determinantes, ¿cómo narra este libro la vida pública del hombre fuerte de la Confederación Argentina? En particular, ¿cómo aborda el tema al que se refiere el subtítulo del libro, la construcción de su posición de poder? Creo que conviene distinguir dos momentos analíticos en el relato que nos ofrecen Fradkin y Gelman, que se corresponden con las etapas previa y posterior a la llegada de Rosas a la gobernación de Buenos Aires en 1829. En cuanto al primer momento, la principal novedad que aporta este trabajo es, me parece, la relevancia analítica otorgada al fenómeno miliciano, poco atendido en las biografías anteriores. En este trabajo, sin embargo, la relación entre Rosas y las milicias de campaña es central en la explicación de la emergencia de este gran estanciero como una figura de relieve en la sociedad rural bonaerense en el curso de la década de 1820 y, de hecho, nos ofrece la principal clave explicativa para entender el ciclo que lo proyectó a la gobernación y al primer plano de la política nacional.

La relación entre Rosas y las milicias de la campaña sirve de eje analítico a la primera mitad del libro. Es en esas páginas, me parece, donde el aporte de las contribuciones previas de Fradkin es más evidente. Los trabajos que este autor ha venido dando a conocer en la última década sobre la cuestión miliciana en las décadas posteriores a Mayo nos han permitido entender mejor una serie de cuestiones vinculadas a la relación entre las formas de la guerra y el orden rural. Gracias a sus estudios, hoy sabemos de la importancia de esas formaciones armadas, de su íntima relación con la sociedad local, de sus límites como forma de poder estatal, de sus conflictos y tensiones con el ejército regular y con formas más amplias y remotas de autoridad. En este libro, el foco de la atención se desplaza desde las poblaciones campesinas en tanto soldados de la república agraria hacia las formas de liderazgo que surgen en ese marco. Es allí donde el liderazgo de Rosas es situado. Pues fue su condición de oficial miliciano y luego de jefe del 5to. Regimiento de milicias de la campaña, más que de gran estanciero o de líder social, la que le permitió proyectar su poder y su prestigio más allá de su entorno rural inmediato. De acuerdo a la visión que nos proponen Fradkin y Gelman, fueron estas peculiares estructuras militares cuerpos armados hondamente arraigados en la comunidad rural- la gran plataforma que le abrió el camino para su ascenso hacia el centro del escenario político de la campaña.

Desde mi punto de vista, estamos ante un hallazgo valioso. El relato del ascenso político de Rosas centrado en su condición de gran terrateniente siempre fue problemático; también lo era, sin embargo, la visión alternativa (aunque en ocasiones también complementaria) que enfatizaba que la clave de su poder debía buscarse menos en su posición económica y social que en su carisma. Las limitaciones de ambas perspectivas son evidentes. Los recursos 
económicos, la gravitación social y el ascendiente personal pueden haber ayudado a un sujeto como Rosas a escalar posiciones en la carrera del poder. Es dudoso, sin embargo, que por sí solos hayan resultado decisivos para que este gran estanciero conquistara una posición política preeminente. No parece sencillo imaginar que un sujeto, por más rico y carismático que fuera, podía alcanzar un papel protagónico en la vida pública de una sociedad compleja como la bonaerense de ese tiempo sin apoyos específicamente políticos y sin recursos institucionales que lo auxiliaran en esa tarea. $\mathrm{Y}$ es a partir de esta premisa que cobra gran relevancia el estudio de Rosas como jefe miliciano pues, como muestra este trabajo, fue este cuerpo armado el que le ofreció una base institucional a partir de la cual expandir su universo de relaciones políticas y acrecentar su prestigio y su autoridad. Fue allí, en definitiva, donde encontró los recursos que le permitieron valorizar sus enormes talentos para el mando y convertirse en una de las figuras más prominentes de la campaña. La narrativa de Fradkin y Gelman sigue con atención las idas y vueltas de esta etapa inicial de la vida pública de Rosas, explorando distintos ejes analíticos, pero el gran argumento que explica su marcha hacia la cumbre gira en torno a este eje: su condición de jefe miliciano.

No hay duda de que esta línea de indagación nos ayuda a explicar la trayectoria de Rosas como líder rural, y su creciente protagonismo a lo largo de la década que culmina con su llegada a la gobernación en 1829. Un importante aspecto a destacar es que los autores nos muestran que este ascenso, lejos de ser sencillo y lineal, enfrentó resistencias que Rosas no siempre logró doblegar. Lo que dicen sobre Chascomús, por largos años un territorio hostil para Rosas, es revelador de un problema más general. A la luz de estas evidencias, hay que renunciar de manera definitiva a la imagen algo romántica y esquemática que ve al señor de Los Cerrillos como el jefe indiscutido de una campaña sólidamente encuadrada en sus lealtades.

El señalamiento de que incluso en el ámbito en el que se movía con más comodidad encontró trabas para afirmar su autoridad invita a orientar esta línea de razonamiento en otra dirección. Y ello porque parece razonable esperar que esos obstáculos se hubiesen revelado aún más significativos en aquellos espacios en los que su base de poder era considerablemente más estrecha. Entre ellos se destaca la ciudad, que para fines de la década de 1820 ya tenía una larga historia de politización. De allí que sea importante preguntarse cómo hizo Rosas para edificar su liderazgo en un medio que conocía poco y en el que nunca se sintió del todo a gusto (recordemos que pasó su etapa formativa en la campaña y, luego de llegar a la gobernación, apenas pudo dejó la ciudad para fijar su residencia en las afueras, en Palermo; su exilio en Inglaterra también fue rural).

En relación a este punto, la visión de Fradkin y Gelman es menos original. El libro menciona una serie de ámbitos de actividad y una serie de 
acciones singulares pero no tenemos un argumento sustantivo que enhebre todo esto en una historia política del Rosas líder urbano que sirva a la vez como narración y como explicación. Sin duda, Rosas invierte tiempo y recursos en la política urbana: se ocupa de auxiliar materialmente a sus seguidores, los invita a jugar al billar en su casa, insta a su esposa Encarnación a distribuir dinero y regalos entre los pobres urbanos y la población negra, promueve y financia la guerrilla de prensa con la que hostiliza a sus rivales, etc. Todo ello es bastante conocido pero, me parece, sigue siendo insuficiente para entender cómo Rosas se convirtió en un líder urbano y, en particular, qué es lo que hizo que su figura apareciera ante los ojos de las clases populares de la ciudad como una oferta política distinta y mejor. Más que una carencia propia de este trabajo, ello pone de manifiesto limitaciones más generales de nuestra historiografía. Nos recuerda que conocemos poco sobre la historia política urbana del segundo cuarto del siglo XIX. En particular, las formas de constitución de prestigio y autoridad política que predominan en este ámbito y las maneras de relación entre las clases populares y las elites políticas son temas que siguen reclamando mayor atención.

Hay un segundo momento en el relato que se enfoca en Rosas jefe de estado, esto es, al período que se abre luego de 1829 y, con mayor claridad, a partir de 1835. En este nuevo escenario, los argumentos invocados para explicar cómo se construyó y/o reforzó su liderazgo político colocan en el centro la cuestión de los recursos que ofrece el poder estatal. El mundo de las milicias campesinas cede protagonismo analítico, desplazado por argumentos y evidencias que refieren al estado en tanto realidad de poder, con sus cristalizaciones institucionales. La perspectiva con la que el problema es abordado debe mucho a las contribuciones previas sobre el tema ofrecidas por Jorge Gelman.

Por una parte, afirma el trabajo, en la década de 1830 se observan iniciativas y progresos en la tarea de construir un estado mejor enraizado en el nivel local, esto es, un estado menos dependiente de los apoyos locales que hasta ese momento le habían servido de base. Entonces se advierte una aceleración del proceso de separación entre el reino de la sociedad y el del poder público. Los autores nos muestran de qué manera Rosas impulsa este movimiento. Por una parte, desarrollan una línea de indagación que toma por eje y punto de observación a la justicia de paz. Las ceremonias a través de las cuales los jueves de paz son investidos de autoridad interpelan a estos actores como agentes de un estado que proclama no deberle nada al poder local. Y el carácter faccioso que adopta el estado rosista, que en formaciones estatales más maduras podría tener un efecto negativo sobre su autoridad y su legitimidad, también apunta en el mismo sentido, pues contribuye a desarraigar al poder público de la influencia de los poderosos y las redes de poder locales que tan 
cruciales habían sido durante el período colonial y en las primeras décadas republicanas.

Este proceso de autonomización del estado también es analizado en relación con las transformaciones experimentadas por el ejército profesional. Desde su llegada a la gobernación, el Restaurador promovió el fortalecimiento del ejército a expensas de los cuerpos milicianos. A partir de ese momento, las formaciones que habían sido su principal punto de apoyo en las etapas iniciales de su carrera iban quedando en un segundo plano. Para ello fue necesario que el ejército, depurado a través de una gran purga de oficiales unitarios, adquiriese una neta coloración punzó, que mantuvo hasta el final de la dictadura.

En síntesis, en la década de 1830, gracias a las transformaciones de la justicia de paz y, en especial, de la forja de un ejército educado en la lealtad a Rosas, comenzó una etapa donde creció el margen de autonomía del estado frente a los actores del mundo social. Esto, nos dicen los autores, sucedió tanto en el campo como en la ciudad (aunque, nuevamente, el argumento resulta más consistente para el primero de estos espacios). No es casual que fuese entonces cuando el Restaurador por fin se sintió lo suficientemente seguro como para lanzar a sus tropas a grandes tareas fuera de la provincia. Ese ejército disciplinado y depurado se erigió en el verdadero núcleo del poder rosista en la etapa de consolidación del régimen. De hecho, el libro sugiere que su ascendiente dependió menos de apoyos sociales -en el relato tanto la lealtad popular como la adhesión elitista ocupan un segundo plano- que de la concentración de recursos de autoridad en el estado. De este modo, Fradkin y Gelman parecen colocarse en la línea interpretativa que asigna gran relevancia a la capacidad del estado decimonónico para actuar como un actor político autónomo.

Este argumento se reafirma con otro razonamiento paralelo: en esos años terminó de cerrarse la crisis hegemónica abierta con la independencia. El libro señala al año 1835 como el hito que sirve como punto de llegada de este proceso. Para esa fecha las turbulentas clases populares que Rosas se había propuesto disciplinar se habían transformado en un pueblo "manso y bondadoso", según citan los autores de manera aprobatoria a un testigo del momento, Juan M. Gutiérrez (pp. 261-262). Si para entonces las heridas abiertas en los años de la Revolución y reabiertas por la rebelión rural de 1828-9 habían cicatrizado, la cuestión de cómo gobernar a las clases populares pasó a colocarse en un plano más rutinario. Las concesiones e intercambios con los actores del mundo plebeyo continuarían signando a la política rosista hasta sus últimos días, pero el principal problema que desde entonces debió enfrentar este régimen pasó a ubicarse en el otro polo del mundo social. Su momento más dramático fue el desafío propietario surgido en el marco de la gran la crisis de 1838-40, que incluyó la rebelión de los estancieros del sur. Ese episodio culminó 
con una inapelable victoria del ejército profesional y de las fuerzas movilizadas por Rosas (dentro de las que se destacan los indios amigos) sobre las milicias rurales organizadas por los jefes estancieros.

La derrota de los Libres del Sur en la primavera de 1839 fue seguida por una dura venganza: el embargo de las propiedades rurales de los terratenientes unitarios que se sumaron a la revuelta o mostraron simpatía por ella. Ese fue el punto máximo de la tensión entre la elite rural y el gobierno de Rosas. Una vez vencidos los desafíos al poder rosista de ese trienio de hondas divisiones a la vez políticas y sociales, lentamente, el poder estatal continuó afianzándose, apoyado sobre el ejército y sobre un sistema de control del territorio más articulado y poderoso, cuyo eje eran los juzgados de paz. En ese contexto se produjo un nuevo acercamiento entre el estado rosista y las clases propietarias. Fradkin y Gelman nos recuerdan, sin embargo, que el hiato nunca terminó de cerrarse y que, hasta el final, el núcleo del sistema de poder rosista radicó en el ejército. Es por ello que, en definitiva, la derrota militar de Caseros arrastraría consigo al régimen.

Muchos elementos de importancia quedan fuera de este breve recorrido por algunos de los argumentos centrales de este libro, enfocado en el tema que dio motivo a esta reunión. No me extenderé sobre cómo los autores abordan otras cuestiones relevantes y a las que dedican páginas muy valiosas. La frontera y la política indígena, o las relaciones interprovinciales e internacionales, se cuentan entre ellos. En el espacio que me resta, me gustaría hacer un último comentario sobre el enfoque del trabajo, y sobre su ubicación en relación con el género biográfico. Retomando el argumento que adelanté al comienzo de ese comentario, quisiera enfatizar que nos encontramos ante una biografía peculiar. Y ello se debe a que, desde el punto de vista analítico, el trabajo de Fradkin y Gelman opta por no colocar en el centro de sus preocupaciones a Rosas en tanto actor político.

Aun cuando este estudio fue publicado en una colección de biografías, su foco es el escenario político y el régimen rosista más que la figura de Rosas. Y ello no solo porque no nos dice mucho sobre cómo piensa y cuáles son sus dilemas personales, cómo se representa su acción, o cómo es su familia y su vida privada. Lo que es más importante, los autores han elegido interpretar y comprender al Restaurador, ante todo, como un producto de su contexto. El relato suele concebirlo como un actor que comprende como nadie cuáles son las fuerzas que operan en el escenario público, qué tipo de restricciones acotan los cursos de acción posibles y qué caminos tiene abiertos (Rosas sabía que era necesario actuar de tal o cual manera para resolver el problema que planteaban los indígenas; Rosas tenía claro hasta donde se podía presionar a los milicianos, etc.) y que, a partir de estos parámetros, orienta su acción. Sin embargo, en esta biografía las decisiones y las acciones del protagonista no suelen presentarse como factores de importancia para entender los avatares o el resultado del 
proceso histórico. Es decir, Rosas no es presentado como un actor situado en un escenario de relativa incertidumbre y que, sobre la base de información confusa, parcial e incompleta, utiliza sus enormes talentos políticos para decidir ciertos cursos de acción y descartar otros. El hecho de que los autores no recurran sino en contadas ocasiones a la abundante y muy rica correspondencia personal de Rosas (el tipo de fuente más apropiada para explorar este tipo de dilemas) es revelador. Del mismo modo, el estudio tampoco presta mayor atención a las posibles consecuencias de sus acciones sobre el curso del proceso político.

Adoptada por historiadores que conocen el período con tanta sofisticación como Fradkin y Gelman, esta forma de abordaje tiene un potencial analítico indudable. Protege, además, contra la tentación, muy propia del género biográfico, de tomar como un dato lo que debería ser pensado como un problema, esto es, del peligro de narrar sin explicar. El enfoque elegido, sin embargo, tiene algunas limitaciones. Entre ellas la más relevante es que tiende a dejar en un segundo plano el problema del biografiado en tanto actor político, en particular en lo que se refiere a su capacidad para modificar el escenario en el que le toca desenvolverse. Y esta cuestión posee especial relevancia en el caso de Rosas, sobre todo desde que este personaje alcanzó la gobernación del estado de Buenos Aires. Pues estamos ante un hombre público de una gravitación enorme, cualitativamente distinto a los otros analizados o mencionados en esta reunión: de José Miguel Carrera y José Hernández, e incluso del propio Manuel Dorrego. Rosas fue, como todos ellos, un producto de su tiempo. Pero fue mucho más que eso, y en grado superlativo. No solo contribuyó a forjar un régimen muy idiosincrático sino que tuvo una incidencia sobre la vida pública y el tejido social que no reconoce paralelo en el siglo XIX. En este sentido, su mayor originalidad como líder político radica no tanto en su capacidad para comprender el cuadro de fuerzas en el que debía moverse sino en su deseo de torcerlas de maneras nuevas y originales.

En algunos casos, las acciones de Rosas tuvieron un impacto indirecto y difícil de estimar no solo para los contemporáneos sino también para los historiadores que, casi dos siglos más tarde, continúan interpretándolas y analizando sus efectos. Esto vale para sus iniciativas dirigidas a profundizar la politización popular y a empujarla en ciertas direcciones y en determinados contextos; vale, asimismo, para sus acciones orientadas a humillar, debilitar (e incluso expropiar) a amplios segmentos de las clases propietarias.

Si la osadía que revela este tipo de iniciativas nos hace sospechar que Rosas fue algo más que un producto de su contexto, al girar la atención sobre un segundo tipo de acciones se pone de relieve la necesidad de llevar este argumento algo más allá. Me refiero a las instancias en las que, enfrentado a ciertos dilemas o en determinadas coyunturas, Rosas eligió cursos de acción que no eran los únicos posibles y que a veces ni siquiera eran los más previsibles o los que gozaban de mayor consenso entre los hombres que debía 
gobernar. Tres ejemplos, aquí presentados bajo la forma de interrogantes, quizás sirvan para ilustrar este punto. En la década de 1830, ¿la marcha de la Confederación por un camino que llevaba a la división de la comunidad política $\mathrm{y}$ al terror administrativo puede entenderse sin incorporar en la ecuación la propia acción de Rosas? En segundo lugar, ¿Rosas no incidió también de manera decisiva en la demora constitucional que coincidió con su paso por la gobernación de Buenos Aires? Finalmente, ¿el estado de guerra permanente en el que vivió la Confederación durante los años de su gobierno puede explicarse sin considerar sus visiones y preferencias personales?

Cuando buscamos respuestas a estas preguntas parece difícil ver de qué manera el esfuerzo por situar a Rosas como un producto de su tiempo resulta suficiente para entender los rasgos más singulares de su acción política. Hay aquí un plus que remite a los aspectos indeterminados de la acción política que, sin necesidad de recurrir a la tentación psicologista (por el momento de escasa utilidad en los estudios históricos) el género biográfico puede ayudarnos a sacar a la luz. Pues este tipo de abordaje, a la vez que nos revela la importancia de situar a un personaje en su entorno, también nos ofrece la posibilidad de desplazar el foco de observación de modo de colocar al contexto en un segundo plano y centrar la atención en los elementos (ideas y experiencias, convicciones y valores, temores y prejuicios) que resulta imprescindible atender si es que se quiere alcanzar una comprensión más plena de las acciones y del legado de un personaje.

No quisiera que esta observación fuese tomada como una impugnación a esta valiosa contribución. Por ello, me gustaría terminar señalando que estamos ante un notable exponente de la renovación historiográfica del tiempo que corre entre Lynch y nuestros días. De hecho, es difícil pensar en un trabajo que analice la sociedad bonaerense de la primera mitad del siglo XIX en tantos planos y con tanta solvencia como los que explora este ensayo. Con todo, este magnífico fresco de la era rosista nos revela que todavía nos queda una tarea pendiente para explicar al Restaurador y también, en alguna medida, para explicar el rosismo: nos falta saber más sobre el factor Rosas. Esto es, nos resta explorar de qué manera el curso del proceso político fue impactado por la acción de este extraordinario personaje, un actor sin el cual no es posible comprender del todo esa historia. 